\title{
Measuring the Quality of Palliative Care for Patients with End-Stage Liver Disease
}

\author{
Arpan Patel ${ }^{1}$ (1) $\cdot$ Steven Asch ${ }^{1} \cdot$ Anna Liza Antonio $^{1} \cdot$ Fasiha Kanwal $^{1} \cdot$ Karl Lorenz $^{1} \cdot$ Deborah Riopelle $^{1}$. \\ Anna Dickey ${ }^{1} \cdot$ Jennifer Larkin ${ }^{1} \cdot$ Martin Lee $^{1} \cdot$ Anne Walling $^{1}$
}

Received: 9 August 2019 / Accepted: 27 November 2019 / Published online: 11 January 2020

(c) This is a U.S. Government work and not under copyright protection in the US; foreign copyright protection may apply 2020

\begin{abstract}
Background/Aims We examined the quality of palliative care received by patients with decompensated cirrhosis using an explicit set of palliative care quality indicators (QIs) for patients with end-stage liver disease (PC-ESLD).

Methods We identified patients newly diagnosed with decompensated cirrhosis at a single veterans health center and followed up them for 2 years or until death. We piloted measurement of PC-ESLD QIs in all patients confirmed to have ESLD using a chart abstraction tool.

Results Out of 167 patients identified using at least one sampling strategy, 62 were confirmed to meet ESLD criteria with chart abstraction. Ninety-eight percent of veterans in the cohort were male, mean age at diagnosis was 61 years, and $74 \%$ were White. The overall QI pass rate was 68\% (64\% for information care planning QIs and 76\% for supportive care QIs). Patients receiving specialty palliative care consultation were more likely to receive information care planning QIs (67\% vs. $37 \%, p=0.02$ ). The best performing sampling strategy had a sensitivity of $62 \%$ and specificity of $60 \%$.

Conclusion Measuring the quality of palliative care for patients with ESLD is feasible in the veteran population. Our singlecenter data suggest that the quality of palliative care is inadequate in the veteran population with ESLD, though patients offered specialty palliative care consultation and those affected by homelessness, drug, and alcohol abuse may receive better care. Our combination of ICD-9 codes can be used to identify a cohort of patients with ESLD, though better sensitivity and specificity may be needed.
\end{abstract}

Keywords Palliative care $\cdot$ Cirrhosis $\cdot$ Healthcare quality $\cdot$ Veterans $\cdot$ End of life

\author{
Abbreviations \\ ICD-9 CM International Classification of Diseases, 9th \\ Revision, Clinical Management \\ CDW Corporate data warehouse
}

\section{Introduction}

End-stage liver disease (ESLD) is a morbid, costly condition characterized by advanced fibrosis of the liver and limited residual hepatocyte function [1]. Fifty percent of patients with ESLD will die within 2 years of their index decompensation, and while liver transplantation is a definitive cure, it is available to a limited number of patients [2]. For example,

Arpan Patel

arpan.patel2@va.gov

1 West Los Angeles Veterans Affairs Medical Center, Los Angeles, USA there were 38,170 reported deaths from ESLD in the USA in 2014, while only 7237 liver transplants were performed for all forms of liver disease [3, 4]. The supportive needs of patients with ESLD are also high. Their symptom burden is comparable to patients with advanced lung and colon cancer in the last 6 months prior to death, and Medicare beneficiaries with cirrhosis also report greater functional disability and use of healthcare utilization compared to age-matched controls and patients with heart failure $[5,6]$.

Despite the immense morbidity and high burden of palliative issues in patients with ESLD, a growing body of literature suggests that referral to services that can provide adequate symptom control and coordination of end-of-life care for this population is generally poor. Only $29 \%$ of Medicare beneficiaries from 2007 to 2011 with ESLD were referred to hospice within 3 years of an index hospitalization despite the fact that $77 \%$ of the same cohort were re-hospitalized and $56 \%$ died in the same follow-up period [7]. In a national study examining in-hospital deaths of patients with ESLD 
from 2009 to 2013, use of invasive life-sustaining treatments was high with $56 \%$ percent of patients receiving mechanical ventilation, $16 \%$ receiving hemodialysis, and $6 \%$ receiving cardiopulmonary resuscitation. However, only $30 \%$ of patients received palliative care, which was associated with reduced procedure burden, lower costs, and lower lengths of stay [8].

A lack of clear guidelines to help healthcare teams deliver high-quality palliative care and coordinate end-of-life care for patients with ESLD is evident, though these have long been a priority for subspecialty organizations treating cancer and other non-chronic conditions such as heart failure, chronic obstructive pulmonary disease, and end-stage renal disease [9-12]. Nineteen quality indicators (QIs) for palliative care in ESLD were recently selected using the RAND/ UCLA appropriateness method (RAM) [13]. Our study's primary aim was to pilot the use of these QIs to measure the quality of palliative care delivered to veterans with ESLD. The Veterans Affairs (VA) Health System is the largest provider of care for patients with hepatitis $\mathrm{C}$, and given the rising incidence of ESLD in this population, optimizing palliative care in this population is particularly crucial [14-16]. Our secondary aim is to compare the sensitivity and specificity of three different sampling strategies used in previous research to identify patients with ESLD within the veteran population.

\section{Methods}

\section{Cohort Identification}

We identified a cohort of veterans from a single VA health system, the VA Greater Los Angeles (GLA) Healthcare System, that had been newly diagnosed with ESLD in the year 2012 using VA Corporate Data Warehouse (CDW). We first included patients using any of the following three different sampling strategies reported in the literature: (1) at least one International Classification of Diseases, 9th edition (ICD9) code for cirrhosis plus at least one ICD-9 code for liver decompensation [17], (2) at least one ICD-9 code for liver decompensation during an inpatient hospitalization (limited to ascites, spontaneous bacterial peritonitis (SBP), or variceal hemorrhage), and (3) at least two ICD-9 codes for liver decompensation (limited to ascites, SBP, or variceal hemorrhage) [18]. We only included patients with at least one outpatient visit or one hospitalization at the GLA VA. In order to capture a population of patients that were newly decompensated, patients with any ICD-9 code for liver decompensation in 2011 were excluded (Table 1).

Next, we used a chart abstraction tool to confirm clinical documentation of a diagnosis of cirrhosis in the medical record as well as criteria for ESLD (MELD score greater than or equal to 20 or a Child-Turcotte-Pugh (CTP) score of 12 or greater from 2012 to 2013). To ensure a minimum amount of time to measure the quality of palliative care, only patients alive for at least 30 days following initial diagnosis of ESLD were included in the final sample. Interrater agreement between 2 chart abstractors used for this study was determined by randomly selecting $10 \%$ of patient charts to determine how frequently both abstractors agreed on the criteria for screening in or screening out patients for inclusion in our final cohort.

\section{Development of Quality Indicators for Palliative Care in ESLD}

A previous publication highlighted the procedure involved in developing and validating these QIs developed to be used with medical record abstraction using the RAM [13]. This process involved multiple steps, including review of guidelines, development of candidate quality indicators, and convening of an expert multidisciplinary panel for review of these indicators to determine appropriateness using a modified Delphi approach. From this analysis, 13 information and care planning and 6 supportive care QIs were chosen.

\section{Full Medical Record Abstraction of Quality Indicators}

Medical records were abstracted from time of diagnosis for 2 years or until death. A full chart abstraction tool

Table 1 Sampling strategies used for identification of ESLD

\begin{tabular}{l}
\hline 1 At least 1 ICD-9 code for cirrhosis ${ }^{\mathrm{a}}$ and at least 1 ICD-9 code for liver decompensation ${ }^{\mathrm{b}}$ \\
At least 1 ICD-9 code for liver decompensation during an inpatient admission (limited to only ascites, spontaneous bacterial \\
peritonitis, and variceal hemorrhage $)^{\mathrm{c}}$ \\
At least 2 ICD-9 codes for liver decompensation (limited to ascites, spontaneous bacterial peritonitis, or variceal \\
hemorrhage $^{\mathrm{c}}$
\end{tabular}

${ }^{\text {a }}$ ICD-9 codes for cirrhosis include 571.2, 571.5, 571.6

${ }^{\mathrm{b}}$ ICD-9 codes for liver decompensation include 789.5, 789.59, 572.3, 456.0, 456.20, 456.2, 456.1, 456.21, 567.0, 567.2, 567.21, 567.23, 567.29, $567.8,567.89,567.9,572.2,572.4$

${ }^{c}$ ICD-9 codes for liver decompensation (limited to ascites, spontaneous bacterial peritonitis, or variceal hemorrhage) include 789.5, 789.59, 572.3 , 456.0, 456.20, 456.2, 456.1, 456.21, 567.0, 567.2, 567.21, 567.23, 567.29, 567.8, 567.89, 567.9 
with guidelines and training materials was developed to measure all 19 palliative care quality indicators for ESLD, as well as criteria used to determine numerators and denominators for each QI. A patient who was eligible for a QI received a score of 1 if the recommended process measure was received; otherwise, they received a score of 0 . Pass rates were calculated by dividing the number of times the QIs were passed over the number of eligible patients for that QI. We abstracted information on patient demographics, homelessness, history of substance abuse, history of viral hepatitis $\mathrm{C}$, history of hepatocellular cancer, documentation pertaining to liver transplant evaluation, and receipt of specialty palliative care services. We also calculated overall quality scores by domain as an average across the domain measures and stratified scores based on variables of interest to explore how different patient characteristics are associated with the quality of palliative care provided. Two-sided Fisher's exact tests were used to compare the categorization of domain-level quality scores by patient characteristics. Interrater reliability on receipt of quality indicators was determined by calculating the kappa coefficient for each numerator and denominator for a $20 \%$ subset of our final sample that were abstracted separately by two abstractors. The confidence intervals for sensitivity and specificity are exact binomial confidence intervals constructed using the method of Clopper and Pearson. [19].

\section{Comparison of Sampling Strategies}

In order to compare the various sampling strategies used to identify patients with ESLD, we calculated the sensitivity and specificity of each of the strategies separately against a gold standard of the screening abstraction tool.

\section{Results}

\section{Descriptive Statistics of Patient Cohort}

We identified 167 patients from the VA CDW that met at least one of our three sampling strategies in 2012. Out of this sample, 71 patients were identified to be true positives using the screening chart abstraction tool, while 96 were screened out because either MELD and Child-Pugh cutoffs were too low or laboratory data were missing. Since 9 patients of the included cohort died within 30 days of diagnosis, our final sample contained 62 patients. Our interrater agreement for screening for a $10 \%$ sample $(N=17)$ was $100 \%$ (Fig. 1$)$. Our final sample had a mean age at diagnosis of 61 years; all but one patient were male, $74 \%$ were White, and 53\% were either single, separated, divorced, or widowed. Sixty-six percent of patients had died by the end of the study period. Seventy-six percent of patients were exempt from co-pay, $36 \%$ were homeless, and $10 \%$ lived in supportive housing. Seventy-nine percent of patients had a history of tobacco use, and $66 \%$ reported a history of drug or alcohol abuse. Sixteen percent of patients had a diagnosis of liver cancer,

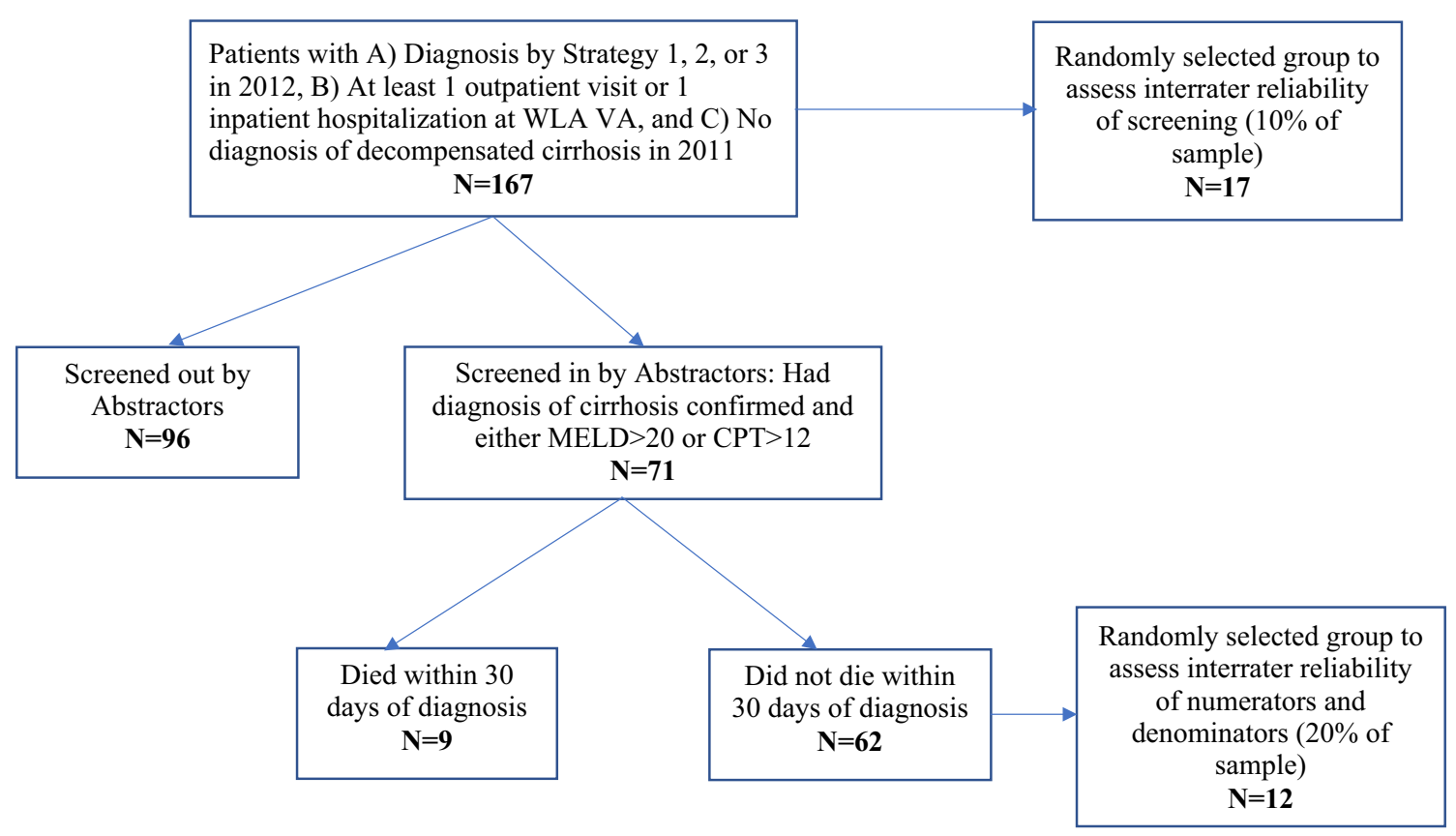

Fig. 1 Flow diagram for cohort identification process 
and $60 \%$ of patients had a diagnosis of hepatitis C. Forty-two percent of patients had no documentation of whether they were being considered for liver transplant, $48 \%$ were not being considered for transplant, and $10 \%$ were being considered for transplant at the end of the study period. Fortyfive percent received specialty palliative care consultation (Table 2).

\section{Receipt of Quality Indicators}

Our cohort of 62 patients triggered 245 information care planning QIs, of which 157 (64\%) were passed, and 118 supportive care QIs, of which 90 (76\%) were passed. The overall pass rate was $68 \%$. Seventeen out of 19 QIs were triggered at least twice with a denominator range of 2-62. Interrater agreement was good to excellent with denominator simple kappa coefficients ranging from 0.75 to 1 and numerator kappa scores ranging from 0.56 to 1 .

Table 2 Characteristics of newly diagnosed patients with ESLD

\begin{tabular}{ll}
\hline & $\begin{array}{l}\text { Mean (SD) } \\
\text { or N (\%), } \\
\text { Total=62 }\end{array}$ \\
\hline Age at diagnosis & $61(7)$ \\
Sex & \\
Male & $61(98 \%)$ \\
Female & $1(2 \%)$ \\
Race & \\
White & $46(74 \%)$ \\
African-American & $9(15 \%)$ \\
Asian & $1(2 \%)$ \\
Other & $4(7 \%)$ \\
No data & $2(3 \%)$ \\
Marital status & \\
Married & $21(34 \%)$ \\
Lives with significant other & $2(3 \%)$ \\
Single, separated, divorced, or widowed & $32(53 \%)$ \\
No data & $6(10 \%)$ \\
Co-pay exempt & $47(76 \%)$ \\
Homeless & $22(36 \%)$ \\
Lives in supportive living & $6(10 \%)$ \\
Smoker & $49(79 \%)$ \\
History of drug or alcohol use & $41(66 \%)$ \\
Hepatitis C & $37(60 \%)$ \\
Hepatocellular carcinoma (HCC) & $10(16 \%)$ \\
Nransplantation status & \\
No documentation & $26(42 \%)$ \\
Still being considered & $30(48 \%)$ \\
Died & $6(10 \%)$ \\
Received specialty palliative care consultation & $41(66 \%)$ \\
\hline & $28(45 \%)$ \\
\hline
\end{tabular}

Of all patients with ESLD who died during follow-up, $63 \%$ of patients were offered specialty palliative care or hospice within 6 months of death. Out of patients being considered for transplantation, only $55 \%$ were offered advance care planning (ACP) within 3 months of consideration, while only $50 \%$ of patients not considered for transplant were offered ACP. Out of the patients not considered for transplant who were initiated on hemodialysis or received an intracardiac device, only $14 \%$ had timely preferences or goals of care documented. Fifty-eight percent of patients newly diagnosed with hepatic encephalopathy had ACP documented in their chart within a month of that diagnosis, while $91 \%$ percent of patients who died an expected death had evidence of ACP performed within 6 months of death. All patients with ESLD admitted to a hospital or nursing home had the name of their surrogate decision maker identified (or documentation to identify a surrogate decision maker) in the electronic health record.

When receiving treatment in the intensive care unit, only $32 \%$ of patients who survived $48 \mathrm{~h}$ after admission had their care preferences documented and none of the 5 patients receiving mechanical ventilation for $48 \mathrm{~h}$ had goals of care or preferences for mechanical ventilation documented. Only $19 \%$ of patients with advance directive or DNR orders prior to being admitted to a second venue had the DNR present in their medical record at the second venue, but all patients with orders to withhold life-sustaining treatment had their preferences followed.

With regard to treatment of pain, $39 \%$ of patients in the full sample were inappropriately prescribed NSAIDs, while only $7 \%$ had total dosages of Tylenol exceeding 3 grams. Ninety-one percent of patients with symptomatic ascites had paracentesis offered within $48 \mathrm{~h}$ of admission, and none of the 5 patients experiencing dyspnea in the last 3 days had their care of dyspnea documented (Table 3 ).

\section{Stratifying Quality Indicator Receipt by Variables of Interest}

Patients with the highest overall QI pass rates included those who were homeless (75\%), with a history of HCC (71\%), and patients receiving specialty palliative care services (66\%). Those with the lowest rates included patients who did not receive palliative care (44\%) and without history of HCC (57\%). Differences in overall pass proportions by clinical characteristics were not statistically significant.

The highest pass proportions for information planning QIs were observed in patients who were not candidates for liver transplant $(62 \%)$, had a history of HCC $(74 \%)$, and who were homeless (72\%). The lowest pass proportions for information planning were observed in patients who did not receive palliative care services (37\%) and those that did not have HCC (55\%). The difference in information planning QI 
Table 3 Receipt of quality indicators for palliative care in ESLD

\begin{tabular}{|c|c|c|c|}
\hline Domain & Quality indicator (QI) & $\begin{array}{l}\text { Eligible } \\
\text { events } \\
\text { (No.) }\end{array}$ & QIs passed (\%) \\
\hline \multirow[t]{12}{*}{ Information care planning } & & 245 & 64 \\
\hline & $\begin{array}{l}\text { IF a patient with advanced ESLD and HCC with BCLC Stage D is not a candidate for } \\
\text { transplant, THEN the patient should be offered palliative care and/or hospice ser- } \\
\text { vices or a reason why should be documented BECAUSE survival is less likely than } \\
6 \text { months and hospice provides additional support for patients and caregiver/family. }\end{array}$ & 2 & 100 \\
\hline & $\begin{array}{l}\text { IF a patient has advanced end-stage liver disease and is diagnosed with hepatorenal } \\
\text { syndrome and is not a liver transplant candidate, THEN the patient should be offered } \\
\text { palliative and/or hospice services BECAUSE these patients have a poor prognosis } \\
\text { and would benefit from the additional supportive services }\end{array}$ & 5 & 80 \\
\hline & $\begin{array}{l}\text { IF a patient with advanced end-stage liver disease dies, THEN there should be } \\
\text { evidence that he or she has been offered palliative care or hospice within } 6 \text { months } \\
\text { before death BECAUSE palliative care teams can improve a range of patient and } \\
\text { caregiver outcomes }\end{array}$ & 41 & 63 \\
\hline & $\begin{array}{l}\text { IF a patient has advanced end-stage liver disease and is being considered for trans- } \\
\text { plant, THEN the patient should be offered advance care planning within } 3 \text { months } \\
\text { of consideration of transplant or a reason why such a discussion did not occur } \\
\text { BECAUSE effective communication about goals of care is important to ensure that } \\
\text { patient preferences are followed during the course of their illness }\end{array}$ & 20 & 55 \\
\hline & $\begin{array}{l}\text { IF a patient is newly diagnosed with advanced end-stage liver disease and is not } \\
\text { considered for transplant, THEN the patient should be offered advance care planning } \\
\text { within } 3 \text { months or a reason why such a discussion did not occur BECAUSE effec- } \\
\text { tive communication about goals of care is important to ensure that patient prefer- } \\
\text { ences are followed during the course of their illness }\end{array}$ & 16 & 50 \\
\hline & $\begin{array}{l}\text { IF a patient with advanced end-stage liver disease dies an expected death, THEN } \\
\text { there should be documentation of advance care planning in the medical record within } \\
6 \text { months before death BECAUSE a patient's goals and values should guide treat- } \\
\text { ment and life-sustaining care decisions }\end{array}$ & 22 & 91 \\
\hline & $\begin{array}{l}\text { IF a patient with advanced end-stage liver disease is admitted to a hospital or nursing } \\
\text { home, THEN within } 48 \mathrm{~h} \text { of admission the medical record should contain the name } \\
\text { of the patient's surrogate decision maker, or documentation of a discussion to iden- } \\
\text { tify/search for a surrogate decision maker BECAUSE patient's values and prefer- } \\
\text { ences should guide life-sustaining care and patients with end-stage liver disease often } \\
\text { cannot make decisions for themselves }\end{array}$ & 54 & 100 \\
\hline & $\begin{array}{l}\text { IF a patient with advanced end-stage liver disease is newly diagnosed with hepatic } \\
\text { encephalopathy and does not have advance care planning previously documented, } \\
\text { THEN the medical record should document advance care planning or lack of ability } \\
\text { to do so within } 1 \text { month BECAUSE patients with a history of hepatic encephalopa- } \\
\text { thy are at higher risk of lacking capacity to make decisions for themselves and care } \\
\text { should be guided by their goals and preferences }\end{array}$ & 12 & 58 \\
\hline & $\begin{array}{l}\text { IF a patient with advanced end-stage liver disease is admitted to the ICU and survives } \\
48 \mathrm{~h} \text {, THEN within } 48 \mathrm{~h} \text {, the medical record should document that the patient's } \\
\text { preferences for care have been considered or an attempt was made to identify them } \\
\text { BECAUSE patients with end-stage liver disease are at a high risk of requiring life- } \\
\text { sustaining treatment decisions }\end{array}$ & 31 & 32 \\
\hline & $\begin{array}{l}\text { IF a patient with advanced end-stage liver disease requires mechanical ventilation for } \\
\text { greater than } 48 \mathrm{~h} \text {, THEN within } 48 \mathrm{~h} \text { of the initiation of mechanical ventilation, the } \\
\text { medical record should document the goals of care and the patient's preference for } \\
\text { mechanical ventilation or why this information is not available BECAUSE patients' } \\
\text { values and preferences should guide life-sustaining care }\end{array}$ & 5 & 0 \\
\hline & $\begin{array}{l}\text { IF a patient with advanced end-stage liver disease has orders in the hospital or nurs- } \\
\text { ing home to withhold or withdraw a life-sustaining treatment (e.g., DNR, no tube } \\
\text { feeding, no hospital transfer), THEN these treatment preferences should be followed } \\
\text { BECAUSE patients' values and preferences should guide end-of-life care }\end{array}$ & 9 & 100 \\
\hline
\end{tabular}


Table 3 (continued)

\begin{tabular}{|c|c|c|c|}
\hline Domain & Quality indicator (QI) & $\begin{array}{l}\text { Eligible } \\
\text { events } \\
\text { (No.) }\end{array}$ & QIs passed (\%) \\
\hline & $\begin{array}{l}\text { IF a patient with advanced end-stage liver disease who is not a candidate for transplant } \\
\text { has the following: new hemodialysis or placement of a pacemaker or ICD, THEN } \\
\text { within } 1 \text { month prior to the procedure, the medical record should document the goals } \\
\text { of care and the patient's preference for the intervention, BECAUSE a patient's treat- } \\
\text { ment should reflect his or her goals of care }\end{array}$ & 7 & 14 \\
\hline & $\begin{array}{l}\text { IF an inpatient with advanced end-stage liver disease has an advance directive or DNR } \\
\text { at the time of discharge and the patient receives care in a second venue, THEN the } \\
\text { advance directive and/or DNR should be present in the medical record of the second } \\
\text { venue or documentation should acknowledge its existence, its contents, and the rea- } \\
\text { son it is not in the medical record, BECAUSE an advance directive can guide care } \\
\text { only if its existence is recognized and its contents are known }\end{array}$ & 21 & 19 \\
\hline \multirow[t]{7}{*}{ Supportive care } & & 118 & 76 \\
\hline & $\begin{array}{l}\text { IF a patient with advanced end-stage liver disease is receiving acetaminophen, THEN } \\
\text { the total daily dose should not exceed } 3 \text { grams or a reason why the patient is receiv- } \\
\text { ing more should be documented BECAUSE acetaminophen-induced hepatotoxicity } \\
\text { may have serious consequences in cirrhosis }\end{array}$ & 40 & 93 \\
\hline & $\begin{array}{l}\text { IF a patient has advanced end-stage liver disease, THEN the patient should not be } \\
\text { prescribed NSAIDS BECAUSE of the increased risk of renal toxicity and bleeding }\end{array}$ & 62 & 61 \\
\hline & $\begin{array}{l}\text { IF a patient with advanced end-stage liver disease who is not enrolled in hospice } \\
\text { presents with ascites with moderate to severe symptoms (pain, shortness of breath, } \\
\text { or non-reducible hernia), THEN the patient should be offered a paracentesis within } \\
48 \text { h or a reason why not should be documented BECAUSE treatment can improve } \\
\text { patients' symptoms }\end{array}$ & 11 & 91 \\
\hline & $\begin{array}{l}\text { IF a patient with advanced end-stage liver disease is not expected to survive and a } \\
\text { mechanical ventilator is withdrawn or withheld, THEN the medical chart should } \\
\text { document whether the patient has dyspnea BECAUSE dyspnea can be controlled in } \\
\text { the setting of comfort care when mechanical ventilation is withdrawn or withheld }\end{array}$ & N/A & N/A \\
\hline & $\begin{array}{l}\text { IF a patient with advanced end-stage liver disease is not expected to survive and a } \\
\text { mechanical ventilator is withdrawn or withheld, THEN the medical chart should } \\
\text { document whether the patient should receive (or have orders available for) dyspnea } \\
\text { management BECAUSE dyspnea can be controlled in the setting of comfort care } \\
\text { when mechanical ventilation is withdrawn or withheld }\end{array}$ & N/A & N/A \\
\hline & $\begin{array}{l}\text { IF a patient with advanced end-stage liver disease who had dyspnea in the last } 3 \text { days } \\
\text { of life died an expected death, THEN the chart should document dyspnea care and } \\
\text { follow-up BECAUSE dyspnea can be effectively treated with pharmacological } \\
\text { agents }\end{array}$ & 5 & 100 \\
\hline Total & & 363 & 68 \\
\hline
\end{tabular}

pass rate by palliative care receipt was statistically significant $(67 \%$ vs. $37 \%, p=0.02)$. The highest pass proportions for supportive care QIs were observed in patients with a history of homelessness $(87 \%)$ and in patients with history of drug or alcohol abuse $(83 \%)$. The difference in supportive care QI pass proportions by homelessness (87\% vs. $58 \%$, $p=0.02$ ) and history of drug or alcohol abuse (83\% vs. $58 \%$, $p=0.05$ ) were significantly different (Table 4).

\section{Sensitivity and Specificity of Sampling Strategies}

Sensitivities and specificities for the three sampling strategies were calculated and compared. Sampling strategy 1 had the highest sensitivity of $87 \%$ and the lowest specificity at
$22 \%$. Sampling strategy 2 had the highest specificity at $60 \%$ and a sensitivity of $62 \%$ (Table 5).

\section{Discussion}

This pilot study successfully appraised the quality of palliative care delivered to a cohort of decedent veterans who were newly diagnosed with ESLD. The overall receipt of quality palliative care was $68 \%$, which is a low statistic considering the fact that only $10 \%$ had documentation that they were being actively considered for liver transplant at the end of the study period and the population had MELD and Child-Pugh score cutoffs of 20 and 12, which correspond to 
Table 4 Comparison of quality indicatory pass proportions by clinical and demographic characteristics

\begin{tabular}{|c|c|c|c|c|c|c|c|}
\hline Characteristic & $\mathrm{N}$ & $\begin{array}{l}\text { Overall QI pass } \\
\text { proportions }\end{array}$ & $P$ value $^{\mathrm{a}}$ & $\begin{array}{l}\text { Information care planning } \\
\text { QI pass proportion }\end{array}$ & $P$ value & $\begin{array}{l}\text { Supportive care QI } \\
\text { pass proportion }\end{array}$ & $P$ value \\
\hline \multicolumn{8}{|l|}{ Transplant status } \\
\hline $\begin{array}{l}\text { No documenta- } \\
\text { tion or still being } \\
\text { considered }\end{array}$ & 32 & $64 \%$ & 0.79 & $58 \%$ & 0.80 & $82 \%$ & 0.09 \\
\hline $\begin{array}{l}\text { Not considered or } \\
\text { not a candidate }\end{array}$ & 30 & $62 \%$ & & $62 \%$ & & $59 \%$ & \\
\hline \multicolumn{8}{|c|}{ Receipt of specialty palliative care services } \\
\hline Yes & 32 & $66 \%$ & 0.13 & $67 \%$ & 0.02 & $60 \%$ & 0.10 \\
\hline No & 30 & $44 \%$ & & $37 \%$ & & $79 \%$ & \\
\hline \multicolumn{8}{|c|}{ Presence of hepatocellular cancer } \\
\hline Yes & 10 & $71 \%$ & 0.50 & $74 \%$ & 0.50 & $61 \%$ & 1.00 \\
\hline No & 52 & $57 \%$ & & $55 \%$ & & $60 \%$ & \\
\hline \multicolumn{8}{|c|}{ History of Active Drug or Alcohol Use } \\
\hline Yes & 26 & $67 \%$ & 0.79 & $63 \%$ & 1.00 & $83 \%$ & 0.05 \\
\hline No & 36 & $61 \%$ & & $61 \%$ & & $58 \%$ & \\
\hline \multicolumn{8}{|l|}{ Homelessness } \\
\hline Yes & 22 & $75 \%$ & 0.26 & $72 \%$ & 0.41 & $87 \%$ & 0.02 \\
\hline No & 40 & $59 \%$ & & $59 \%$ & & $58 \%$ & \\
\hline
\end{tabular}

${ }^{\text {a }} P$ value for two-sided Fisher's exact test to compare proportions

Table 5 Sensitivity and specificity of various sampling strategies

\begin{tabular}{llll}
\hline & 1 & 2 & 3 \\
\hline Sensitivity (95\% CI) & $87 \%(77.3-94.0 \%)$ & $62 \%(49.7-73.2 \%)$ & $49 \%(37.2-61.4 \%)$ \\
Specificity (95\% CI) & $22 \%(14.1-31.5 \%)$ & $60 \%(48.9-69.3 \%)$ & $57 \%(46.8-67.3 \%)$ \\
\hline
\end{tabular}

$20 \%$ 3-month and 55\% 1-year mortality rates, respectively [20].

Our study found that the receipt of supportive care QIs (76\%) was higher than information care planning QIs (64\%). A similar discrepancy in receipt of QIs by domain was observed in a study investigating quality of end-of-life care in patients with various serious chronic illnesses hospitalized at a major quaternary academic medical center [21]. In our cohort, only about half of patients were offered ACP, whether they were being considered or not considered for liver transplant. Furthermore, ACP was only offered to $58 \%$ of patients with newly diagnosed hepatic encephalopathy, which increases the risk of a patient lacking capacity to make their own decisions. Information care planning practices were even less frequently adopted once patients become hospitalized. Goals of care discussions were documented less than one-third of time and not at all for patients surviving $48 \mathrm{~h}$ after ICU admission and after mechanical ventilation, respectively.

There has been increasing interest in improving ACP in patients with ESLD [22], and our findings suggest that greater attention should be paid to understanding these barriers and describing new clinical models of care. In patients with advanced malignancies, for example, shared mental models have been developed to better provide patients with the support needed to guide and document their future choices [23]. Our findings also suggest a statistically higher receipt of ACP in patients who received specialty palliative care consultation. Recently, VA has implemented a Life-Sustaining Treatment Decisions Initiative (LSTDI) nationally aimed at improving goals of care conversations among veterans with serious illness and future work should evaluate whether this has a positive impact on these quality indicators for veterans with ESLD.

The frequency of palliative care consultation for patients with ESLD who are hospitalized at the end of life has been increasing, though these studies do not incorporate a direct measure of specialty services [8]. In patients who are being evaluated for liver transplant, concurrent specialty palliative care consultation was associated with improvement in symptom burden and depression symptoms after 6 months of follow-up [24]. This study further adds to these findings that specialty palliative care services may provide benefits for patients with ESLD. In addition, our study suggests that referral rates to specialty palliative care in ESLD may be lower than those for veterans with 
advanced cancer, highlighting potential room for improvement [25].

Supportive care QIs were more frequently met, likely owing to the fact that avoidance of high doses of acetaminophen and provision of paracentesis for ascites are wellestablished practices in the management of all patients with ESLD [26]. The avoidance of NSAIDs, however, was not followed $39 \%$ of the time, which may reflect the tension that providers face when only limited options are present to alleviate pain in patients with ESLD, who are at higher risk of adverse events from available pain relief strategies, such as narcotics [27]. Patients with a history of homelessness and history of drug and alcohol abuse were more likely to receive supportive QIs. This runs counter to previous studies that have shown more challenges in access and provision of palliative care in these patient populations but may reflect the high commitment to providing these services in the veteran Health Administration [28-30].

Lastly, a combination of one ICD-9 code for cirrhosis and one ICD-9 code for liver decompensation (limited to ascites, SBP, and variceal hemorrhage) had a sensitivity of $62 \%$ and specificity of $60 \%$ for identifying patients from our total cohort. These moderate values likely reflect the fact that our cohort was focused on a particularly sick population (identified by a MELD score $\geq 20$ and Child-Pugh score $\geq 12$ ).

There are several strengths to our study. Our hierarchical method of identifying patients with ESLD using three different sampling strategies and a chart abstraction tool to confirm diagnosis was highly reliable given the $100 \%$ interrater agreement between abstractors. Our chart abstraction tool to identify QIs for palliative care in patients with ESLD was also both feasible and reliable, given that are interrater agreements were good to excellent. Our findings also highlight significant gaps in the provision of palliative care to patients with ESLD, which are consistent with the currently available literature, suggesting validity of our results.

A few limitations should be highlighted. The findings of this study were performed at a single VA medical center and as such, reported results from a small sample size that cannot be generalized. Certain stratified trends in QI receipt that were not significant using our cohort may be more apparent using a larger cohort of patients. Future work should explore natural language processing and machine learning as potential methods to improve identification of a denominator with higher sensitivity and specificity. The perspectives of veterans with ESLD and caregivers on receipt of palliative care and hospice services should also be collected to help guide future quality improvement work in this field. Our findings demonstrate that it is feasible to measure the quality of palliative care for a veteran cohort of patients with ESLD with good reliability. Our identification of a seriously ill group of patients with ESLD using a combination of ICD-9 codes can be used for future cohort studies in the VA system that are looking to investigate their clinical care and outcomes. Our preliminary findings from this study highlight the need for better information care planning in patients with ESLD, particularly as patients' care becomes more acute, and suggest some benefit in involving specialty palliative care services in improving this goal. We believe our methods for measuring quality of palliative care can be applied to the national veteran population, which can further add to our knowledge of ways to better improve the care of this vulnerable group.

Author's contribution FK, SA, KL, and AW were involved in study concept and design; all authors were involved in data acquisition, analysis, and interpretation; AP, AA, and AW were involved in drafting of manuscript; all authors were involved in critical revision of manuscript; FK, SA, KL, and AW were involved in study supervision ; AW was involved in administrative, technical, or material support; and AA, ML, and AW were involved in statistical analysis. All authors approved the final submitted manuscript.

Funding This research was supported by VA HSR\&D pilot Grant \#121 HX001804. Dr. Patel was supported by the Ruth L. Kirschstein Institutional National Research Service Award (NRSA) for Primary Care T32 (T32HP19001). Dr. Walling was also supported by the Cambia Health Foundation Sojourns Scholar Leadership Program.

\section{Compliance with Ethical Standards}

Conflict of interest The authors declare that they have no conflict of interests.

\section{References}

1. Kamath PS, Wiesner RH, Malinchoc M, et al. A model to predict survival in patients with end-stage liver disease. Hepatology. 2001;33:464-470.

2. D'Amico G, Morabito A, Pagliaro L, et al. Survival and prognostic indicators in compensated and decompensated cirrhosis. Dig Dis Sci. 1986;31:468-475. https://doi.org/10.1007/BF01320309.

3. Kim WR, Lake JR, Smith JM, et al. OPTN/SRTR 2015 Annual Data Report: Liver. Am J Transplant. 2017;17:174-251.

4. Murphy SL, X., Kochanek KD. Deaths: final data for 2010. Updated May 8, 2013. Centers for Disease Control and Prevention website.

5. Rakoski MO, McCammon RJ, Piette JD, et al. Burden of cirrhosis on older Americans and their families: analysis of the health and retirement study. Hepatology. 2012;55:184-191.

6. Roth K, Lynn J, Zhong Z, et al. Dying with end stage liver disease with cirrhosis: insights from SUPPORT. Study to Understand Prognoses and Preferences for Outcomes and Risks of Treatment. J Am Geriatr Soc. 2000;48:S122-30.

7. Brown CL, Hammill BG, Qualls LG, et al. Significant morbidity and mortality among hospitalized end-stage liver disease patients in medicare. J Pain Symptom Manage. 2016;52:412-419.

8. Patel AA, Walling AM, Ricks-Oddie J, et al. Palliative care and health care utilization for patients with end-stage liver disease at the end of life. Clin Gastroenterol Hepatol. 2017;15:1612-1619. 
9. Smith TJ, Temin S, Alesi ER, et al. American Society of Clinical Oncology provisional clinical opinion: the integration of palliative care into standard oncology care. J Clin Oncol. 2012;30:880-887.

10. Hunt SA. ACC/AHA 2005 Guideline Update for the Diagnosis and Management of Chronic Heart Failure in the Adult: a report of the American College of Cardiology/American Heart Association Task Force on Practice Guidelines (Writing Committee to Update the 2001 Guidelines for the Evaluation and Management of Heart Failure): developed in collaboration with the American College of Chest Physicians and the International Society for Heart and Lung Transplantation: endorsed by the Heart Rhythm Society. Circulation. 2005;112:e154-e235.

11. Lanken PN, Terry PB, DeLisser HM, et al. An official American Thoracic Society clinical policy statement: palliative care for patients with respiratory diseases and critical illnesses. Am J Respir Crit Care Med. 2008;177:912-927.

12. Galla JH. Clinical practice guideline on shared decision-making in the appropriate initiation of and withdrawal from dialysis: The Renal Physicians Association and the American Society of Nephrology. J Am Soc Nephrol. 2000;11:1340-1342.

13. Walling AM, Ahluwalia SC, Wenger NS, et al. Palliative care quality indicators for patients with end-stage liver disease due to cirrhosis. Dig Dis Sci. 2017;62:84-92. https://doi.org/10.1007/ s10620-016-4339-3.

14. Yee HS, Chang MF, Pocha C, et al. Update on the management and treatment of hepatitis $\mathrm{C}$ virus infection: recommendations from the Department of Veterans Affairs Hepatitis C Resource Center Program and the National Hepatitis C Program Office. Am J Gastroenterol. 2012;107:669-689.

15. Kanwal F, Hoang T, Kramer JR, et al. Increasing prevalence of $\mathrm{HCC}$ and cirrhosis in patients with chronic hepatitis $\mathrm{C}$ virus infection. Gastroenterology. 2011;140:1182-1188.

16. Julapalli VR, Kramer JR, El-Serag HB, et al. Evaluation for liver transplantation: adherence to AASLD referral guidelines in a large Veterans Affairs center. Liver Transpl. 2005;11:1370-1378.

17. Goldberg D, Lewis D, Halpern SD, et al. Validation of three coding algorithms to identify patients with end-stage liver disease in an administrative database. Pharmacoepidemiol Drug Saf. 2012;21:765-769.

18. Lo Re V III, Lim JK, Goetz MB, et al. Validity of diagnostic codes and liver-related laboratory abnormalities to identify hepatic decompensation events in the Veterans Aging Cohort Study. Pharmacoepidemiol Drug Saf. 2011;20:689-699.

19. Clopper CJ, Pearson ES. The use of confidence or fiducial limits illustrated in the case of the binomial. Biometrika. 1934;26:404-413.
20. Cholongitas E, Papatheodoridis GV, Vangeli M, et al. Systematic review: The model for end-stage liver disease-should it replace Child-Pugh's classification for assessing prognosis in cirrhosis? Aliment Pharmacol Ther. 2005;22:1079-1089.

21. Walling AM, Asch SM, Lorenz KA, et al. The quality of care provided to hospitalized patients at the end of life. Arch Intern Med. 2010;170:1057-1063.

22. Brisebois A, Ismond KP, Carbonneau M, et al. Advance care planning (ACP) for specialists managing cirrhosis: a focus on patientcentered care. Hepatology. 2018;67:2025-2040.

23. D'Ambruoso SF, Coscarelli A, Hurvitz S, et al. Use of a shared mental model by a team composed of oncology, palliative care, and supportive care clinicians to facilitate shared decision making in a patient with advanced cancer. J Oncol Pract. 2016;12:1039-1045.

24. Baumann AJ, Wheeler DS, James M, et al. Benefit of early palliative care intervention in end-stage liver disease patients awaiting liver transplantation. J Pain Symptom Manage. 2015;50:882-886.

25. Walling AM, Tisnado D, Asch SM, et al. The quality of supportive cancer care in the veterans affairs health system and targets for improvement. JAMA Intern Med. 2013;173:2071-2079.

26. Thomson MJ, Tapper EB, Lok ASF. Dos and don'ts in the management of cirrhosis: a view from the 21 st century. Am J Gastroenterol. 2018;113:927.

27. Chandok N, Watt KD. Pain management in the cirrhotic patient: the clinical challenge. Mayo Clin Proc. 2010;85:451-458.

28. Ahmed N, Bestall JE, Ahmedzai SH, et al. Systematic review of the problems and issues of accessing specialist palliative care by patients, carers and health and social care professionals. Palliat Med. 2004;18:525-542.

29. Woods A, Willison K, Kington C, et al. Palliative care for people with severe persistent mental illness: a review of the literature. Can J Psychiatry. 2008;53:725-736.

30. O'Hanlon C, Huang C, Sloss E, et al. Comparing VA and nonVA quality of care: a systematic review. J Gen Intern Med. 2017;32:105-121.

Publisher's Note Springer Nature remains neutral with regard to jurisdictional claims in published maps and institutional affiliations. 